\title{
HMGB1 mediates microglia activation via the TLR4/NF-кB pathway in coriaria lactone induced epilepsy
}

\author{
YUNBO SHI $^{*}$, LINGLI ZHANG ${ }^{2 *}$, JUNFANG TENG $^{1}$ and WANG MIAO ${ }^{1}$ \\ Departments of ${ }^{1}$ Neurology and ${ }^{2}$ Gastroenterology, The First Affiliated Hospital of Zhengzhou University, \\ Zhengzhou, Henan 450052, P.R. China
}

Received February 22, 2017; Accepted October 10, 2017

DOI: $10.3892 / \mathrm{mmr} .2018 .8485$

\begin{abstract}
Epilepsy is a chronic and recurrent disease of the central nervous system, with a complex pathology. Recent studies have demonstrated that the activation of glial cells serve an important role in the development of epilepsy. The objective of the present study was to investigate the role of high-mobility group box-1 (HMGB1) in mediating the activation of glial cells through the toll-like receptor 4 (TLR4)/nuclear factor (NF)- $\kappa \mathrm{B}$ signaling pathway in seizure, and the underlying mechanism. The brain tissue of post-surgery patients with intractable epilepsy after resection and the normal control brain tissue of patients with craniocerebral trauma induced intracranial hypertension were collected. The expression level and distribution pattern of HMGB1, OX42 and NF- $\kappa$ B p 65 were detected by immunohistochemistry. HMGB1, TLR4, receptor for advanced glycation end products (RAGE), NF-кB p65 and inducible nitric oxide synthase (iNOS) expression levels were detected by western blotting, and serum cytokine levels of interleukin (IL)-1, IL-6, tumor necrosis factor (TNF)- $\alpha$, transforming growth factor (TGF)- $\beta$ and IL-10 in patients with epilepsy and craniocerebral trauma were detected by ELISA. And cell model of epilepsy was established by coriaria lactone (CL)-stimulated HM cell, and the same factors were measured. The potential toxic effect of HMGB1 on HM cells was evaluated by MTT and 5-ethynyl-2-deoxyuridine assays. The results demonstrated that compared with the control group, levels of HMGB1, TLR4, RAGE, NF- $\mathrm{kB}$ p65 and iNOS in the brain of the epilepsy group were significantly increased, and increased cytokine levels of IL-1, IL-6, TNF- $\alpha$, TGF- $\beta$ and IL-10 in patients with epilepsy were also observed. At the same time,
\end{abstract}

Correspondence to: Dr Wang Miao, Department of Neurology, The First Affiliated Hospital of Zhengzhou University, 1 Jianshe East Road, Zhengzhou, Henan 450052, P.R. China

E-mail: miaow99@yeah.net

${ }^{*}$ Contributed equally

Key words: epilepsy, high-mobility group box-1, activation of microglia, nuclear factor- $\kappa \mathrm{B}$ p65 the above results were also observed in HM cells stimulated with CL. Overexpression of HMGB1 enhanced the results, while HMGB1 small interfering RNA blocked the function of CL. There was no significant toxic effect of HMGB1 on HM cells. In conclusion, overexpression of HMGB1 potentially promoted epileptogenesis. CL-induced activation of glial cells may act via up-regulation of HMGB1 and TLR4/RAGE receptors, and the downstream transcription factor NF- $\mathrm{\kappa B}$.

\section{Introduction}

Epilepsy is a disease caused by the synchronous abnormal discharge of intracranial neurons, it is predominantly characterized by Convulsive status epilepticus (1). The pathology of epilepsy is a complex process, including genetic factors, brain diseases including intracranial tumor, intracranial infection, craniocerebral injury, cerebrovascular disease, and systemic diseases, such as anoxia, metabolic disease and endocrine disease (2). Epilepsy is a life-threatening neurological disease that affects many people $(3,4)$. Surgery can sometimes result in positive outcomes for patients with drug-resistant seizures (5); however, sometimes completely removing lesions is a problem (6).

A previous study observed that mutational hot spots in the transmembrane domains of calcium voltage-gated channel subunit alpha1 and ATPase/Na+/K+ transporting subunit alpha 2 proteins were highly associated with epilepsy in hemiplegic migraine (7). Brain inflammation is considered serve an important role in epilepsy (8). The pro-inflammatory C5a receptor, C5arl, represents a novel target for improved anti-epileptic drug development, which may be beneficial for pharmaco-resistant patients (9).

Inflammatory processes in the central nervous system (CNS) have been reported to serve a vital role in human epilepsy and in experimental models of seizures (10). CNS inflammation is characterized by a disturbance of glial cell functions: A previous study has demonstrated the direct effects of several antiepileptic drugs (AEDs) on glial viability through detecting the gap junctional network, microglial activation and cytokine expression in an in vitro astroglia/microglia co-culture model (11). Anti-inflammatory therapies both in clinical and in experimental settings obtained a good therapeutic result. All the above highlight the important role of brain inflammation in the aetiopathogenesis of seizures. 
Certain components of the inflammatory gene network might contribute to the process (12).

Glia serve a pivotal role in the initiation and maintenance of the CNS immune response, and it involves in defining central nervous system architecture, brain metabolism, and the survival of neurons, development and modulation of synaptic transmission, propagation of nerve impulses, and many other physiological functions (13). In the recently years, the contribution of glial cells, mainly astrocytes and microglia, to the pathophysiology of epilepsy is increasingly appreciated $(11,14)$.

Microglia are the major immune cells in the brain, and serve an immune monitoring function. They have been traditionally studied in various contexts of disease, and their activation has been assumed to induce mostly detrimental effects (15). Microglia-driven epilepsy may be a primary pathogenic process; experimental and clinical studies support a pathogenic role of microglial activation and proliferation in epileptogenesis (16). Previous studies have demonstrated that microglia activated by recurrent seizures continuously secrete a variety of immune effector molecules, such as interleukin (IL)-1, IL-6, IL-8, tumor necrosis factor (TNF)- $\alpha$, transforming growth factor (TGF)- $\beta$, and oxygen free radicals, such as reactive oxygen species, which can damage other neurons, glial cells and the blood brain barrier, causing local or extensive injury of central nervous system, aggravate epilepsy and cause seizures $(16,17)$.

High-mobility group box 1 (HMGB1) is a nuclear protein with cytokine-type functions upon its extracellular release. HMGB1 activates inflammatory pathways by stimulating multiple receptors, chiefly toll-like receptor 4 (TLR4) and receptor for advanced glycation end products (RAGE) (18). A study on a model of renal ischemic reperfusion injury (IRI) demonstrated that the HMGB1-TLR4 inflammatory signaling pathway was inhibited by dexamethasone treatment via the attenuated translocation of HMGB1 from the nucleus to the cytoplasm, and the down-regulation of TLR4 expression (19). Quercetin has hepatoprotective and anti-fibrotic effects to liver fibrosis through modulating the HMGB1-TLR2/4-nuclear factor $(N F)-\kappa B$ signaling pathways (20). Experimental models of seizures and temporal lobe epilepsy verified that hyperexcitability of HMGB1 and TLR4 signaling leads to the development and perpetuation of seizures (21). IL-1 type 1 receptor/TLR, which can be activated by proinflammatory cytokines such as HMGB1, serves a key role in seizures (22). HMGB1 contributes to the overexpression of P-glycoprotein in mouse epileptic brain tissues via activation of TLR4/RAGE receptors and the downstream transcription factor $\mathrm{NF}-\kappa \mathrm{B}$ in brain microvascular endothelial cells (23).

The present study aimed to explore a novel way for the treatment of intractable epilepsy by targeting microglia and blocking the associated inflammatory signaling pathways, receiving the effect of reducing nerve injury and cytotoxic substance release.

\section{Materials and methods}

Specimen collection. The present study was ethically approved by The First Affiliated Hospital of Zhengzhou University (Zhengzhou, China) and written informed consent was obtained from every participant. Brain tissue was collected post-surgery from both patients with intractable epilepsy (EP group) after resection, and the control brain tissue of patients with craniocerebral trauma induced intracranial hypertension. All brain tissue was frozen in liquid nitrogen.

Immunohistochemical staining (IHC). IHC was performed as previous described (5). Brain tissue sections $(5 \mu \mathrm{m})$ for immunohistochemical analysis were fixed in $4 \%$ paraformaldehyde (Sigma-Aldrich; Merck KGaA, Darmstadt, Germany) and paraffin-embedded. Sections of the brain regions were selected for the IHC study following fixing of the sections with acetone. Briefly, slides were incubated with $0.03 \% \mathrm{H}_{2} \mathrm{O}_{2}$ in PBS for $10 \mathrm{~min}$ at room temperature, then incubated in 5\% normal goat serum in PBS for $15 \mathrm{~min}$. Sections were then incubated with primary antibodies: Anti-HMGB1 (cat. no. ab18256, 1:100; Abcam, Cambridge, UK), anti-NF- $\kappa$ B p65 (cat. no. ab16502, 1:5,000; Abcam) and anti-OX42 (cat. no. ab1211, 1:500; Abcam) in 3\% bovine albumin serum in PBS at $4^{\circ} \mathrm{C}$ overnight. Immunoreactivity was detected using avidin-biotin-peroxidase technique; sections were incubated with 3, 3'-diaminobenzidine as the chromogen for $20 \mathrm{~min}$ at $37^{\circ} \mathrm{C}$. Images were acquired using an upright optical microscope (DM4000; Leica Microsystems, Mannheim, Germany). Prior to mounting, the cell nuclei were counterstained by Hoechst 33342 fluorescent dye (1:1,000; Invitrogen; Thermo Fisher Scientific, Inc., Waltham, MA USA) for $10 \mathrm{~min}$ at $37^{\circ} \mathrm{C}$. Samples without the addition of a primary antibody were used as the negative control. For each field, the number of positively stained capillaries were counted under a light microscope and the percentage of positive cells was calculated from the average value of five fields.

Western blotting. Total protein was extracted from brain tissue or cultured cells in different groups as described previously (24). Protein concentration was determined using a bicinchoninic acid protein assay kit. Proteins (30 $\mu \mathrm{g} /$ lane) were separated using 10\% SDS-PAGE and transferred onto polyvinylidene difluoride membranes. The membranes were incubated overnight with the following primary antibodies: Anti-HMGB1 (cat. no. ab18256; 1:100; Abcam), anti-TLR4 (cat. no. 293072; 1:1,000; Santa Cruz, Biotechnology, Inc., Dallas, TX, USA), anti-RAGE (cat. no. AB15323; 1:1,000; Santa Cruz Biotechnology, Inc.), anti-NF-кB p65 (cat. no. ab16502; 1:5,000; Abcam), anti-inducible nitric oxide synthase (cat. no. 49055; iNOS; 1:200; Abcam) and anti- $\beta$-actin (cat. no. A1978; 1:50,000; Sigma-Aldrich; Merck KGaA) at $4^{\circ} \mathrm{C}$. Subsequently, the membranes were incubated with horseradish peroxidase (HRP)-conjugated anti-rabbit IgG secondary antibody (cat. no. 6721; 1:5,000; Abcam) at $37^{\circ} \mathrm{C}$ for $30 \mathrm{~min}$ and exposed to X-ray film using an enhanced chemiluminescence system (Thermo Fisher Scientific, Inc.). The intensity of the bands was measured using Lab-works (version 4.0; Ultra-Violet Products Ltd., Cambridge, UK).

Reagents and cell lines. Human microglia (HM) cells were obtained from Dr. Dai Antibody's laboratory (Case Western Reserve University, Cleveland, OH, USA) and were cultured as described previously (25). HM cells were cultured in Dulbecco's modified Eagle's medium supplemented with $10 \%$ 
fetal bovine serum (Gibco; Thermo Fisher Scientific, Inc.), $100 \mathrm{U} / \mathrm{ml}$ penicillin-G, $100 \mu \mathrm{g} / \mathrm{ml}$ streptomycin and $0.01 \mathrm{M}$ Hepes buffer (Thermo Fisher Scientific, Inc.) in a humidified $5 \% \mathrm{CO}_{2}$ atmosphere at $37^{\circ} \mathrm{C}$.

HM microglia were stimulated with epileptic agent coriaria lactone (CL), and the expression levels of HMGB1, TLR4, RAGE and p-NF- $\kappa \mathrm{B}$ p65 were detected by western blotting after collecting cells.

Plasmid transfection. Full-length human HMGB1 cDNA was amplified by polymerase chain reaction from pCMV4-RelA plasmid (Shanghai GenePharma Co., Ltd., Shanghai, China) using the forward primer 5'-GGTCGGTACCATGGA CGAACTGTTCCCCCT-3' and the reverse primer 5'-CCA TCTCGAGTTAGGAGCTGATCTGACTCA-3', inserted into a pcDNA3.1 vector (Shanghai GenePharma Co., Ltd.) tagged with FLAG. HMGB1 small interfering (si)RNA (HMGB1-KD) and its control siRNA were purchased from Santa Cruz Biotechnology, Inc. Transient transfection of HM cells with pcDNA3.1/HMGB1 cDNA or control pcDNA3.1, and its control siRNA was carried out using Lipofectamine 2000 reagent (Thermo Fisher Scientific, Inc.) according to the manufacturer's protocol.

Enzyme-linked immunosorbent assay (ELISA). The expression levels of cytokines IL-1 (cat. no. 68616), IL-6 (cat. no. 68834), TNF- $\alpha$ (cat. no. 55845), TGF- $\beta$ (cat. no. 31366) and IL-10 (cat. no. 68540) in the cell culture supernatant were detected by ELISA (MLBIO; Shanghai Enzyme-linked Biotechnology Co., Ltd., Shanghai, China). A 96-well plate was coated with the primary monoclonal antibody of IL- 1, IL- 6, TNF- $\alpha$, TGF- $\beta$ or IL-10. Standards and supernatant samples were added to the wells. Following washing with 5\% non-fat dry milk in PBS with $0.05 \%$ Tween-20 (Sigma-Aldrich; Merck KGaA), the wells were incubated with HRP-conjugated anti-rabbit IgG antibody (cat. no. 6721; 1:1,000; Abcam) for $10 \mathrm{~min}$ at $37^{\circ} \mathrm{C}$. The plate was washed again with the aforementioned solution, followed by incubation with tetramethylbenzidene solution for $15 \mathrm{~min}$ at $37^{\circ} \mathrm{C}$. This reaction was stopped by adding hydrochloride solution. Optical density was measured by using a microplate reader (Bio-Rad 550; Bio-Rad Laboratories, Inc., Hercules, CA, USA) set to $450 \mathrm{~nm}$.

Cytotoxicity/cell viability assay. The potential toxic effect of HMGB1 on HM cells was analyzed using the 3-(4, 5-dimethylthylthiazol-2-yl)-2,5-diphenyltetrazolium bromide (MTT) method. Cells were seeded into 96-well plates at a concentration of $8 \times 10^{3}$ cells per well. After being grown for $24 \mathrm{~h}$, cells were incubated at $37^{\circ} \mathrm{C}$ with either HMGB1 (10, 100 and $500 \mathrm{ng} / \mathrm{ml}$ ) or untreated control medium (PBS), respectively, for different periods of time (4, 8, 16 and $24 \mathrm{~h})$. Subsequently, $50 \mu \mathrm{l}$ MTT tetrazolium salt (Sigma-Aldrich; Merck KGaA) was diluted with PBS to a concentration of $5 \mathrm{mg} / \mathrm{ml}$, then the mixture was added to each well and incubated for another $2 \mathrm{~h}$ at $37^{\circ} \mathrm{C}$. The medium was then aspirated from each well and $200 \mu \mathrm{l}$ dimethyl sulfoxide was added to dissolve the formazan crystals. The resulting solution $(150 \mu \mathrm{l})$ was transferred to a 96-well plate and the absorbance of each well was determined using a Tecan infinite M200 Pro plate reader at a wavelength of $570 \mathrm{~nm}$. Each experiment was replicated three times. The potential toxic effect of CL on HM cells was also analyzed with an MTT assay.

5-ethynyl-2-deoxyuridine (EdU) staining. The EdU assay is a method of detecting proliferating cells with the advantage of being simple and convenient, avoiding DNA denaturation and maintaining the shape of the sample. It has replaced the traditional method of bromodeoxyuridine staining. It is a method of detection of DNA synthesis in proliferating cells and relies on the incorporation of labeled DNA precursors into cellular DNA during the $\mathrm{S}$ phase of the cell cycle (1). EdU staining was conducted using Cell-Light ${ }^{\mathrm{TM}}$ EdU kit (Guangzhou RiboBio Co., Ltd., Guangzhou, China), according to the manufacturer's protocol. Paraffin sections were de-paraffinized in xylene for 10 min twice, rinsed in an alcohol gradient $(100,95,85 \%)$ for $10 \mathrm{~min}$, and rinsed in deionized water for $5 \mathrm{~min}$. After washing with $2 \mathrm{mg} / \mathrm{ml}$ glycine solution diluted in double distilled water for $10 \mathrm{~min}$, the sections were permeabilized with $0.5 \%$ Triton $\mathrm{X}-100$ in PBS for $20 \mathrm{~min}$, and then washed twice with PBS for $10 \mathrm{~min}$. The Apollo reaction buffer liquid, catalyst, fluorescent dyes and buffer additives (Guangzhou RiboBio Co., Ltd.) were dissolved in deionized water, and shaken to make the Apollo 567 staining reaction solution (Guangzhou RiboBio Co., Ltd.). The sections were then incubated for $30 \mathrm{~min}$ without light. The sections were washed twice with PBS for $10 \mathrm{~min}$ at $37^{\circ} \mathrm{C}$. For subsequent DNA staining, sections were counterstained with Hoechst 33342 for $30 \mathrm{~min}$ away from light at $37^{\circ} \mathrm{C}$. The slides were then washed twice with PBS for $3 \mathrm{~min}$, and observed immediately under a fluorescent microscope (magnification, $\mathrm{x} 400$ ). All the procedures were conducted at room temperature. EdU-positive cells were detected by an Olympus BX51 microscope (Olympus Corporation, Tokyo, Japan). Images of the ApolloW 567 were captured with a 'red' filter set: Excitation, $550 \mathrm{~nm}$; emission, $565 \mathrm{~nm}$; filter, $555 \pm 15 \mathrm{~nm}$. Images of the Hoechst 33342 were captured with a 'blue' filter set: Excitation, $350 \mathrm{~nm}$; emission, $461 \mathrm{~nm}$; filter, $405 \pm 15 \mathrm{~nm}$.

Statistical analysis. All data are expressed as the mean \pm standard deviation. The statistical analyses were performed using GraphPad Prism 6.0 software (GraphPad Prism Inc., USA). Comparison between two groups was performed by unpaired Student's t-test. Comparison among multiple groups was performed by one-way analysis of variance with a least significant difference post-hoc test. $\mathrm{P}<0.05$ was considered to indicate a statistically significant difference.

\section{Results}

Expression and distribution of $H M G B 1, N F-\kappa B$ p 65 and OX42 in the epileptic brain tissues of patients with refractory epilepsy brain tissue. To explore the expression level and changes in the distribution pattern of HMGB1 in epileptic brain tissues, resection of brain tissue after surgery was collected. The distribution of HMGB1, NF- $\kappa \mathrm{B}$ p65 and OX42 in the control and EP group was observed using IHC. In the control group, HMGB1 immunoreactivity was detected mostly in the nuclei of the glial cells and pyramidal neurons. In the EP group, cytoplasmic staining of HMGB1 was significantly increased in the pyramidal neurons (Fig. 1). Next to glial cells with nuclear staining, glial cells with both 


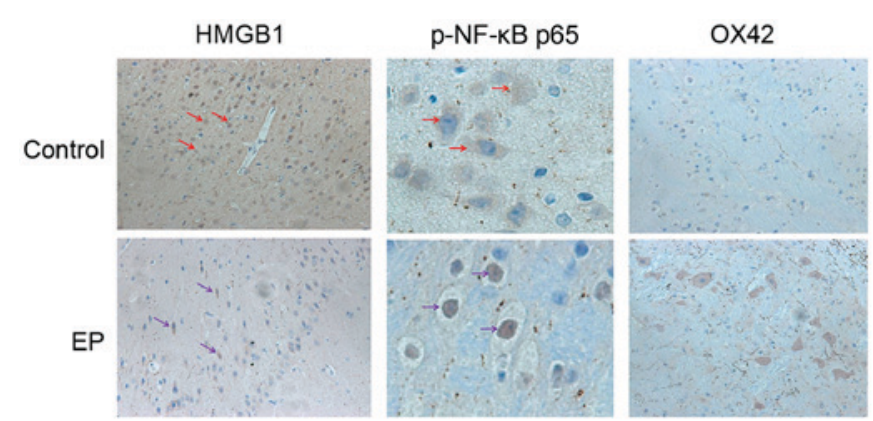

Figure 1. Expression and distribution of HMGB1, NF- $\kappa B$ p65 and OX42 in the epileptic brain tissues of patients with refractory epilepsy. HMGB1, high-mobility group box-1; p-, phosphorylated; NF- $\mathrm{B}$, nuclear factor- $\mathrm{B}$; $\mathrm{EP}$, refractory epilepsy group. Red and purple arrows indicate the protein distribution of HMGB1 and NF-кB p65, respectively. Magnification, x200.
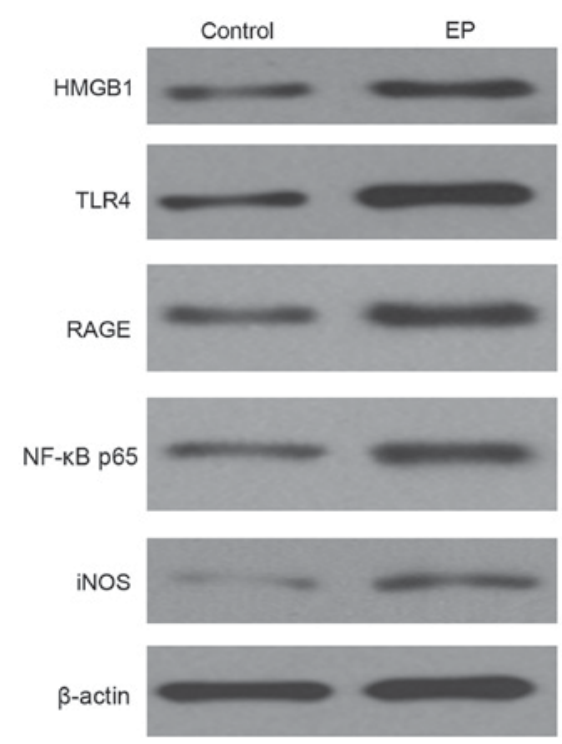

Figure 2. Expression level of HMGB1, TLR4, RAGE, NF-кB p65 and iNOS in the brain tissues of the control and the EP group, as detected by western

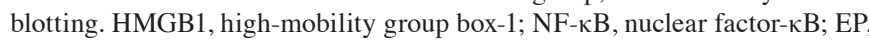
refractory epilepsy group; TLR4, toll-like receptor 4; RAGE, receptor for advanced glycation end products; iNOS, inducible nitric oxide synthase.

nuclear and cytoplasmic staining were also present. These results indicated the nuclear to cytoplasmic translocation of HMGB1 in neurons and glial cells, and predicted its subsequent release into the extracellular space. Higher expression levels of NF- $\kappa \mathrm{B}$ p 65 were detected in the EP group in comparison with the control group. Positive NF- $\kappa \mathrm{B}$ p65 staining was detected mainly in the cell nucleus in the EP group, suggesting the cytoplasmic to nuclear translocation of $\mathrm{NF}-\mathrm{KB}$ p65 in neurons and glial cells. Next, IHC staining of the brain tissues of patients was conducted, using a marker for reactive microglia (OX42). The results reflected that the cell density of the two was similar.

Comparing the level of HMGB1, TLR4, RAGE, NF- $\kappa B$ p65 and iNOS in the brain tissues of the control and the EP groups. To investigate the expression level of HMGB1, TLR4, RAGE, NF- $\mathrm{kB}$ p65 and iNOS in the control and the EP brain tissues, western blotting was performed. From the result, HMGB1 was notably increased, and the TLR4 and

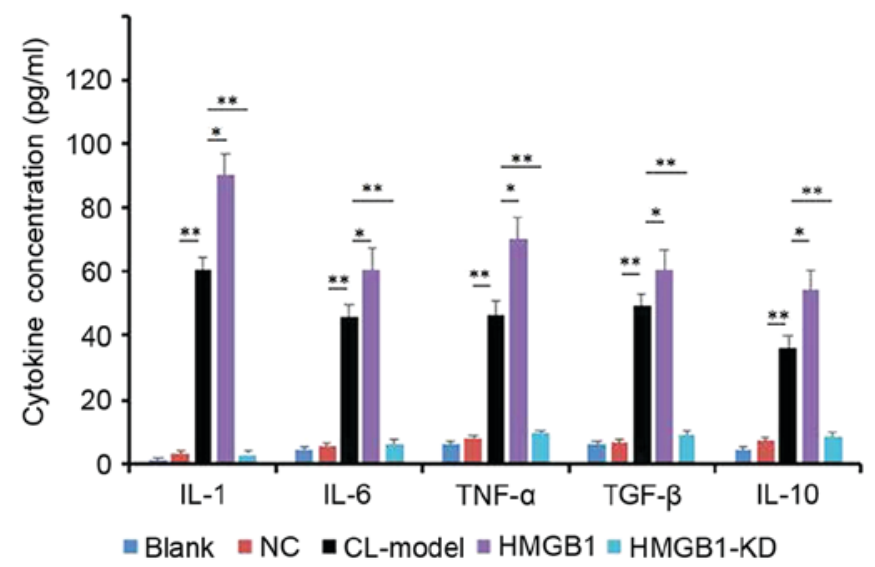

Figure 3. Levels of cytokines, as detected by ELISA. HM cells were induced by $\mathrm{CL}$, then transfected with HMGB1 mimic and HMGB1-KD. Data are presented as the mean \pm standard deviation. ${ }^{*} \mathrm{P}<0.05,{ }^{* *} \mathrm{P}<0.01$. HMGB1, high-mobility group box-1; NC, negative control; IL, interleukin; TNF, tumor necrosis factor; TGF, transforming growth factor; CL-Model, cariaria lactone induced epilepsy cell model; CL-HM, cariaria lactone induced epilepsy cell model plus HMGB1; CL-HM-KD, cariaria lactone induced epilepsy cell model plus HMGB1 siRNA; siRNA, small interfering RNA; HMGB1-KD, HMGB1 siRNA.

RAGE signaling pathway was markedly activated; their expression levels were both significantly increased. Both genetic and biochemical data support that TLR4 and RAGE signaling pathway could eventually lead to the activation of NF- $\mathrm{KB}$ (23). Thus, in the present study, upregulation of NF- $\kappa \mathrm{B}$ was observed (Fig. 2).

Comparing the level of cytokines of $I L-1, I L-6, T N F-\alpha$, $T G F-\beta$ and $I L-10$ in the cell supernatant of the control and the $C L$-induced epileptic cell model. To determine the levels of cytokines of IL-1, IL- 6 , TNF- $\alpha$, TGF- $\beta$ and IL-10 in the cell supernatant of the control and the CL-induced epileptic cell model, ELISA was used to determine the concentration of each cytokine. From the result (Fig. 3), CL effectively enhanced the level of the all the above cytokines, and induced overexpression of HMGB1.

Expression of HMGB1,TLR4, RAGE and NF- $\kappa B$ p65 in $H M$ cells. Western blotting was used to detect expression of HMGB1, TLR4, RAGE and NF-кB p65 in HM cells. From the result (Fig. 4A), CL appeared to increase the levels of HMGB1, TLR4, RAGE, NF- $\mathrm{kB}$ p65 and iNOS in HM cells; overexpression of HMGB1 enhanced this result (Fig. 4B), and inhibition of HMGB1 with HMGB1-KD blocked the function of CL to HM cells.

$H M G B 1$ had no significant effect on the viability of HM cells. As presented in Fig. 5, the overexpression of HMGB1 did not significantly decrease the viability of HM cells at any tested concentrations or time points, compared with the control cells. Additionally, incubation with CL followed by overexpression also had no effect on the viability of HM cells.

EdU assay. To determine the proliferation of HM cells, an EdU assay was used. Similar to the MTT results, there were no significant differences among each group (Fig. 6), which 
A
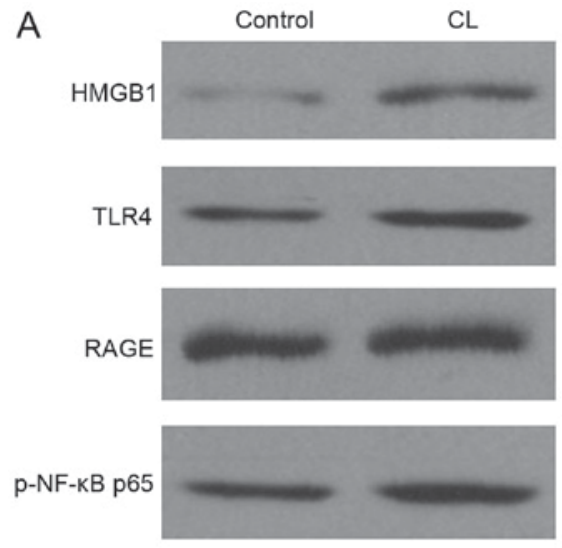

$\beta$-actin

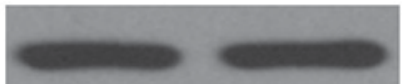

B
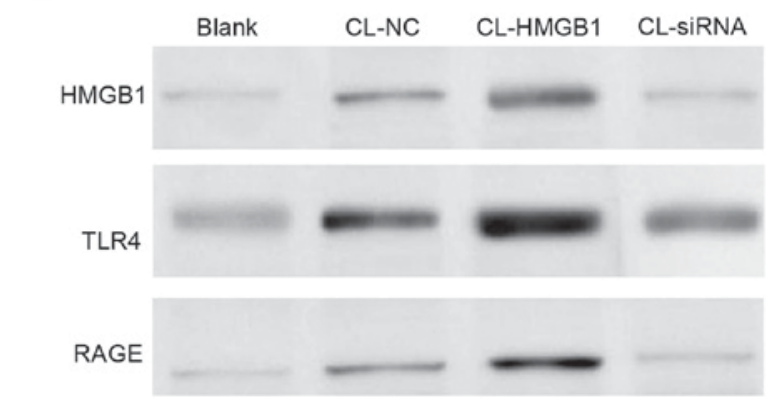

p-NF-KB p65

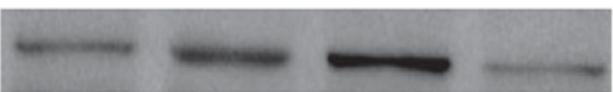

$\beta$-actin

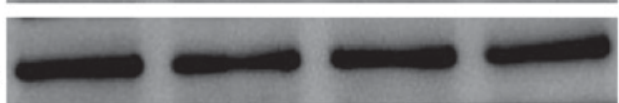

Figure 4. Western blotting of protein expression levels in HM cells. (A) CL significantly increases the levels of HMGB1, TLR4, RAGE, NF- $\mathrm{kB}$ p65 and iNOS in HM cells. (B) Overexpression of HMGB1 this increased further, and inhibition of HMGB1 by siRNA blocked the function of CL to HM cells. HMGB1,

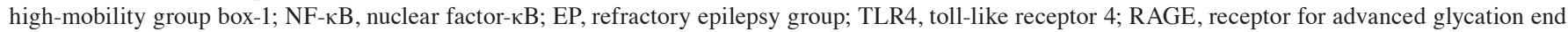
products; iNOS, inducible nitric oxide synthase; p-phosphorylated; siRNA, small interfering RNA; NC, negative control; CL, cariaria lactone.
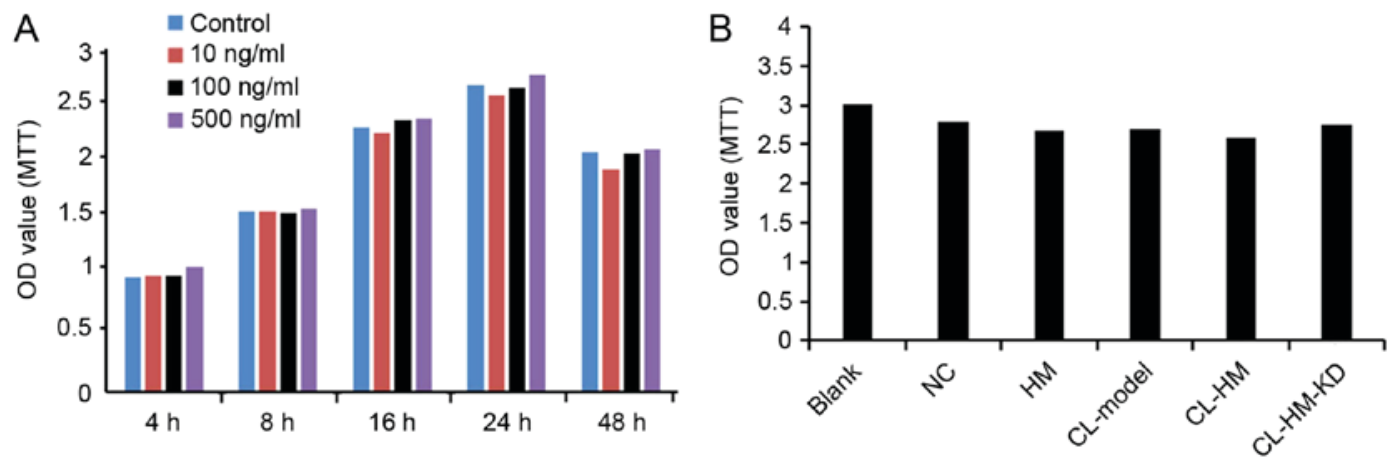

Figure 5. HMGB1 has no significant effect on viability of HM cells. (A) Cells were transfected with different concentrations of HMGB1 for the indicated time periods. Cell viability was determined using MTT assay. (B) Comparison of cell viability in each group of Blank, NC, HM, CL-Model, CL-HM and CL-HM-KD. Data from three independent experiments are presented as the mean \pm standard deviation ( $\mathrm{n}=3$ ). HMGB1, high-mobility group box-1; Blank, blank group; NC, negative control group; HM, HMGB1; CL-Model, cariaria lactone induced epilepsy cell model; CL-HM, cariaria lactone induced epilepsy cell model plus HMGB1; and CL-HM-KD, cariaria lactone induced epilepsy cell model plus HMGB1 siRNA; OD, optical density.
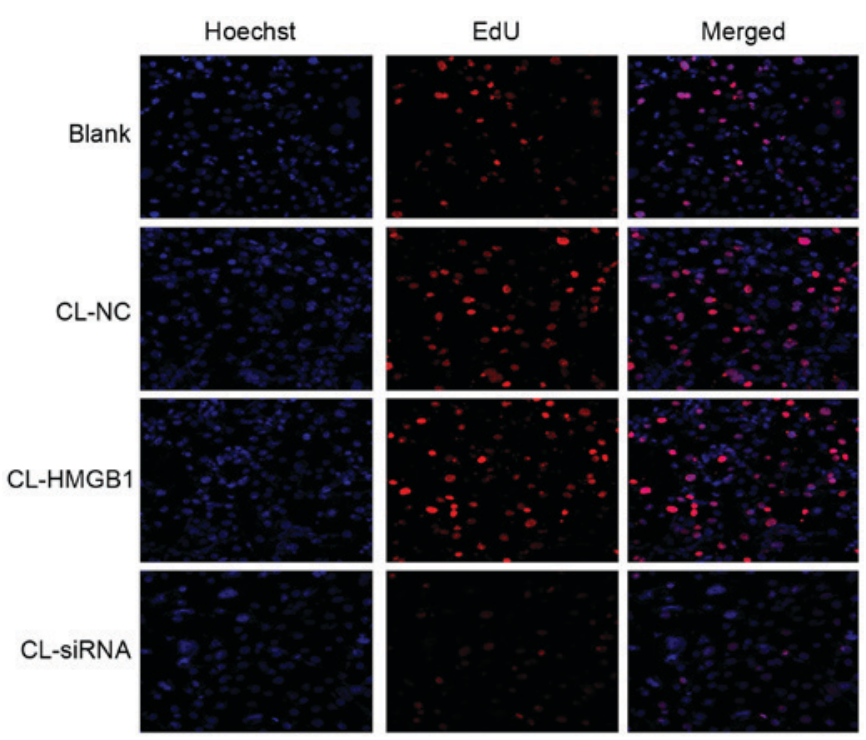

Figure 6. HM cell proliferation was detected by EdU assay. Magnification, x100. CL, cariaria lactone; NC, negative control; HMGB1, high-mobility group box-1; siRNA, small interfering RNA; EdU, 5-ethynyl-2-deoxyuridine. reflects that HMGB1 and CL had no significant effect on the proliferation of HM cells.

\section{Discussion}

Epilepsy is a common disease of the central nervous system, with common symptoms including frequent repetitive muscle jerks, usually arrhythmic, which severely threatens the health of many people $(18,26,27)$. The treatment methods include chemotherapy conservative treatment and surgery (28). However, neither of them can definitely receive encouraging results (29). The pathology for this disease is very complex, including genetic factors, CNS inflammation, and brain diseases and disorders (30). Among them, CNS inflammation has attracted increasing attention (10).

The role of complement system-mediated inflammation is of key interest in seizure and epilepsy pathophysiology (9). Administration of selective serotonin reuptake inhibitors could lessen their antidepressant effect over time. as well as elevated seizure outcomes observed in people with 
epilepsy (4). A previous study demonstrated that microglial cells in epileptic rats feature widespread, activation-associated morphological changes such as increase in cell number density, massive up-regulation of CD11b and de-ramification (14). In gliomas, microglia and macrophages represent a significant component of the inflammatory response, and the balance of pro- and anti-inflammatory functions of them dictates their antitumor activity (31). Recent evidence implicates glial cells and neuroinflammation in the pathogenesis of epilepsy, with the promise of targeting these cells to complement existing strategies (32).

HMGB1 is a central late pro-inflammatory cytokine that triggers the inflammatory response. Our study verified the role of HMGB1 in regulating brain injury in the epileptic brain tissues of patients. A previous study demonstrated that expression of HMGB1, TLR2, TLR4 and RAGE were up-regulated in rasmussen encephalitis (33). Another study also revealed cell loss and neurogenesis, which involve inflammatory signaling pathways, were upregulated in human epilepsy (34).

The HMGB1-TLR2/4-NF- $\mathrm{KB}$ signaling pathways is a classic inflammatory signaling pathway (19-22), usually involved in mediating multiple inflammatory pathways, and during this process, microglia activation releases cytokines. HMGB1 may signal through TLR4, and results in the activation of NF- $\mathrm{KB}$, which participates in regulation of inflammation and activation of immune cells (35). In addition, knockdown of HMGB1 expression significantly inhibits the expression levels of NF- $\mathrm{kB} / \mathrm{p} 65$ and suppresses the nuclear translocation and DNA-binding activity of NF-kB/p65 (36).

In conclusion, the present study demonstrated that the epileptogenous agent CL effectively increased HMGB1 and cytokines levels in HM cells, which had the similar result of brain tissue of post-surgery patients with intractable epilepsy, while overexpression of HMGB1 could aggravate this result, and inhibition of HMGB1 could block that result. These results suggested that HMGB1 serves a vital role in epileptogenesis through microglial activation, via TLR4-NF- $\mathrm{kB}$ signaling pathway activation. The present study provided evidence for a clinical treatment method for the patients with epilepsy. The development of a novel, non-invasive biomarker for HMGB1 may allow early identification of patients at high risk of developing epilepsy.

\section{References}

1. Snoeijen-Schouwenaars FM, van Ool JS, Tan IY, Schelhaas HJ and Majoie MH: Evaluation of perampanel in patients with intellectual disability and epilepsy. Epilepsy Behav 66: 64-67, 2017.

2. Gavvala JR and Schuele SU: New-onset seizure in adults and adolescents: A review. JAMA 316: 2657-2668, 2016.

3. Pohlmann-Eden B, Aldenkamp A, Baker GA, Brandt C, Cendes F, Coras R, Crocker CE, Helmstaedter C, Jones-Gotman M, Kanner AM, et al: The relevance of neuropsychiatric symptoms and cognitive problems in new-onset epilepsy-Current knowledge and understanding. Epilepsy Behav 51: 199-209, 2015.

4. Singh T and Goel RK: Managing epilepsy-associated depression: Serotonin enhancers or serotonin producers? Epilepsy Behav 66 : 93-99, 2017.

5. Jehi LE, Palmini A, Aryal U, Coras R and Paglioli E: Cerebral cavernous malformations in the setting of focal epilepsies: Pathological findings, clinical characteristics and surgical treatment principles. Acta Neuropathol 128: 55-65, 2014.

6. Zubkov S and Friedman D: Epilepsy treatment and creativity. Epilepsy Behav 57: 230-233, 2016.
7. Prontera P, Sarchielli P, Caproni S, Bedetti C, Cupini LM, Calabresi $\mathrm{P}$ and Costa $\mathrm{C}$ : Epilepsy in hemiplegic migraine: Genetic mutations and clinical implications. Cephalalgia, 2017 (Epub ahead of print).

8. Wang C, Ding H, Tang X, Li Z and Gan L: Liuweibuqi capsules suppress inflammation by affecting $\mathrm{T}$ cell polarization and survival in chronic obstructive pulmonary disease. Med Chem Res 26: 2816-2823, 2017.

9. Okuneva O, Li Z, Körber I, Tegelberg S, Joensuu T, Tian L and Lehesjoki AE: Brain inflammation is accompanied by peripheral inflammation in Cstb-/-mice, a model for progressive myoclonus epilepsy. J Neuroinflammation 13: 298, 2016.

10. Benson MJ, Thomas NK, Talwar S, Hodson MP, Lynch JW, Woodruff TM and Borges K: A novel anticonvulsant mechanism via inhibition of complement receptor C5ar1 in murine epilepsy models. Neurobiol Dis 76: 87-97, 2015.

11. Alyu F and Dikmen M: Inflammatory aspects of epileptogenesis: Contribution of molecular inflammatory mechanisms. Acta Neuropsychiatr 29: 1-16, 2017.

12. Dambach H, Hinkerohe D, Prochnow N, Stienen MN, Moinfar Z, Haase CG, Hufnagel A and Faustmann PM: Glia and epilepsy: Experimental investigation of antiepileptic drugs in an astroglia/microglia co-culture model of inflammation. Epilepsia 55: 184-192, 2014.

13. Patterson KP, Brennan GP, Curran M, Kinney-Lang E, Dubé C, Rashid F, Ly C, Obenaus A and Baram TZ: Rapid, coordinate inflammatory responses after experimental febrile status epilepticus: Implications for epileptogenesis. eNeuro 2, 2015.

14. von Bernhardi R, Eugenín-von Bernhardi J, Flores B and Eugenín León J: Glial cells and integrity of the nervous system. Adv Exp Med Biol 949: 1-24, 2016

15. Papageorgiou IE, Fetani AF, Lewen A, Heinemann U and Kann O: Widespread activation of microglial cells in the hippocampus of chronic epileptic rats correlates only partially with neurodegeneration. Brain Struct Funct 220: 2423-2439, 2015.

16. Luo C, Ikegaya Y and Koyama R: Microglia and neurogenesis in the epileptic dentate gyrus. Neurogenesis (Austin) 3: e1235525, 2016.

17. Najjar S, Pearlman D, Miller DC and Devinsky O: Refractory epilepsy associated with microglial activation. Neurologist 17: 249-254, 2011.

18. Mazarati A, Maroso M, Iori V, Vezzani A and Carli M: High-mobility group box-1 impairs memory in mice through both toll-like receptor 4 and receptor for advanced glycation end products. Exp Neurol 232: 143-148, 2011

19. Zhang J, Xia J, Zhang Y, Xiao F, Wang J, Gao H, Liu Y, Rong S, Yao Y, Xu G and Li J: HMGB1-TLR4 signaling participates in renal ischemia reperfusion injury and could be attenuated by dexamethasone-mediated inhibition of the ERK/NF- $\mathrm{B}$ pathway. Am J Transl Res 8: 4054-4067, 2016.

20. Li X, Jin Q, Yao Q, Xu B, Li Z and Tu C: Quercetin attenuates the activation of hepatic stellate cells and liver fibrosis in mice through modulation of HMGB1-TLR2/4-NF- $\mathrm{kB}$ signaling pathways. Toxicol Lett 261: 1-12, 2016.

21. Zurolo E, Iyer A, Maroso M, Carbonell C, Anink JJ, Ravizza T, Fluiter K, Spliet WG, van Rijen PC, Vezzani A and Aronica E: Activation of Toll-like receptor, RAGE and HMGB1 signalling in malformations of cortical development. Brain 134: 1015-1032, 2011.

22. Maroso M, Balosso S, Ravizza T, Liu J, Bianchi ME and Vezzani A: Interleukin-1 type 1 receptor/Toll-like receptor signalling in epilepsy: The importance of IL-1beta and high-mobility group box 1. J Intern Med 270: 319-326, 2011.

23. Chen Y, Huang XJ, Yu N, Xie Y, Zhang K, Wen F, Liu H and Di Q: HMGB1 contributes to the expression of P-glycoprotein in mouse epileptic brain through toll-like receptor 4 and receptor for advanced glycation end products. PLoS One 10: e0140918, 2015.

24. Ratovitski T, Chaerkady R, Kammers K, Stewart JC, Zavala A, Pletnikova O, Troncoso JC, Rudnicki DD, Margolis RL, Cole RN and Ross CA: Quantitative proteomic analysis reveals similarities between huntington's disease (HD) and huntington's disease-like 2 (HDL2) human brains. J Proteome Res 15: 3266-3283, 2016.

25. Smith AM, Gibbons HM, Oldfield RL, Bergin PM, Mee EW, Curtis MA, Faull RL and Dragunow M: M-CSF increases proliferation and phagocytosis while modulating receptor and transcription factor expression in adult human microglia. J Neuroinflammation 10: 85, 2013. 
26. Delahaye-Duriez A, Srivastava P, Shkura K, Langley SR, Laaniste L, Moreno-Moral A, Danis B, Mazzuferi M, Foerch P, Gazina EV, et al: Rare and common epilepsies converge on a shared gene regulatory network providing opportunities for novel antiepileptic drug discovery. Genome Biol 17: 245, 2016.

27. Mameniskiene R and Wolf P: Epilepsia partialis continua: A review. Seizure 44: 74-80, 2017.

28. Ertürk Çetin Ö, İşler C, Uzan M and Özkara Ç: Epilepsy-related brain tumors. Seizure 44: 93-97, 2017

29. Falco-Walter J, Owen C, Sharma M, Reggi C, Yu M, Stoub TR and Stein MA: Magnetoencephalography and new imaging modalities in epilepsy. Neurotherapeutics 14: 4-10, 2017.

30. Loscher W, Hirsch LJ and Schmidt D: The enigma of the latent period in the development of symptomatic acquired epilepsyTraditional view versus new concepts. Epilepsy Behav 52: 78-92, 2015.

31. Zhang I, Alizadeh D, Liang J, Zhang L, Gao H, Song Y, Ren H, Ouyang M, Wu X, D'Apuzzo M and Badie B: Characterization of arginase expression in glioma-associated microglia and macrophages. PLoS One 11: e0165118, 2016.

32. Eyo UB, Murugan M and Wu LJ: Microglia-neuron communication in epilepsy. Glia 65: 5-18, 2017.
33. Luan G, Gao Q, Zhai F, Chen Y and Li T: Upregulation of HMGB1, toll-like receptor and RAGE in human Rasmussen's encephalitis. Epilepsy Res 123: 36-49, 2016.

34. Iori V, Maroso M, Rizzi M, Iyer AM, Vertemara R, Carli M, Agresti A, Antonelli A, Bianchi ME, Aronica E, et al: Receptor for advanced glycation endproducts is upregulated in temporal lobe epilepsy and contributes to experimental seizures. Neurobiol Dis 58: 102-114, 2013.

35. van Beijnum JR, Buurman WA and Griffioen AW: Convergence and amplification of toll-like receptor (TLR) and receptor for advanced glycation end products (RAGE) signaling pathways via high mobility group B1 (HMGB1). Angiogenesis 11:91-99, 2008.

36. Huang Z, Zhong Z, Zhang L, Wang X, Xu R, Zhu L, Wang Z, $\mathrm{Hu} S$ and Zhao X: Down-regulation of HMGB1 expression by shRNA constructs inhibits the bioactivity of urothelial carcinoma cell lines via the NF-кB pathway. Sci Rep 5: 12807, 2015.

This work is licensed under a Creative Commons Attribution-NonCommercial-NoDerivatives 4.0 International (CC BY-NC-ND 4.0) License. 